\title{
Riscos de contaminação e os impactos pela disposição de efluente de laticínios em latossolo vermelho amarelo
}

Objetivou com este estudo, determinar o risco de contaminação e os impactos que podem causar os íons de sódio, potássio, cálcio e magnésio, presentes na água residuária de laticínios, por meio de ensaios em colunas de lixiviação. Para isso, foram montadas colunas a partir da deposição sucessiva de camadas de solo com dois centímetros de espessura e sua posterior compactação no interior do tubo de PVC até formação de uma coluna com 0,15 $\mathrm{m}$ de altura, posteriormente foram saturadas com água destilada e utilizando frascos de Mariotte se aplicou as doses correspondentes a zero, 250; 625; 1250; 2500 mg L-1 de Na de efluente de laticínios. Os lixiviados foram coletados, determinando-se as concentrações de $\mathrm{Na}$, $\mathrm{Ca}$, Mg e K por espectrofotometria de absorção atômica. Os resultados do ensaios em colunas de lixiviação demonstraram a preferência de interação de $\mathrm{K}>\mathrm{Ca}>\mathrm{Na}>\mathrm{Mg}$, independentemente da diluição do efluente, seguindo-se a ordem de reatividade dos íons. Esses resultados alertam o cuidado quanto à disposição deste, uma vez que a interação entre os solutos presentes na água residuária de laticínios com o solo em caso de aplicação inadequada, pode resultar na salinização do solo e até mesmo em salinização do lençol freático devido a lixiviação do sódio.

Palavras-chave: Reúso; Coluna de Lixiviação; Mobilidade de Íons.

\section{Contamination risks and impacts caused by the disposal of dairy effluent in red-yellow latosol}

\begin{abstract}
Objective with this study, was to determine the risk of contamination and the impacts that the sodium, potassium, calcium and magnesium ions present in dairy waste water can cause by leach column tests. For this, columns were assembled from the successive deposition of layers of soil with two centimeters of thickness and their subsequent compaction in the interior of the PVC tube until formation of a column with $0,15 \mathrm{~m}$ of height, later they were saturated with distilled water and using Mariotte vials the doses corresponding to zero, $250 ; 625 ; 1250 ; 2500 \mathrm{mg} \mathrm{L}-1 \mathrm{Na}$ of effluent from dairy products. The leachates were collected, determining the concentrations of $\mathrm{Na}, \mathrm{Ca}, \mathrm{Mg}$ and $\mathrm{K}$ by atomic absorption spectrophotometry. The results of the tests in leach columns showed the interaction preference of $\mathrm{K}>\mathrm{Ca}>\mathrm{Na}>\mathrm{Mg}$, regardless of the dilution of the effluent, following the order of reactivity of the ions. These results alert the care of the disposition of this, since the interaction between the solutes present in the wastewater of dairy with the soil in case of inadequate application, can result in the salinization of the soil and even in salinization of the water table due to leaching of sodium
\end{abstract}

Keywords: Reuse; Leaching Column; Mobility of lons.

José Antônio Rodrigues de Souza (10) Instituto Federal Goiano Campus Urutaí, Brasil http://lattes.cnpq.br/1637300776838940 http://orcid.org/0000-0003-3024-9424 jose.antonio@ifgoiano.edu.br

\section{Débora Astoni Moreira (ic}

Instituto Federal Goiano Campus Urutaí, Brasil http://lattes.cnpq.br/0892554192927049 http://orcid.org/0000-0002-8658-1269 debora.astoni@ifgoiano.edu.br

\section{Éllen Lemes Silva (iD)}

Instituto Federal Goiano Campus Urutaí, Brasil http://lattes.cnpq.br/2020996967548069 http://orcid.org/0000-0001-5649-5055 ellen_cbba@hotmail.com

\author{
Walisson Marques Oliveira (iD \\ Instituto Federal Goiano Campus Urutaí, Brasil \\ http://lattes.cnpq.br/7052217868475846 \\ http://orcid.org/0000-0002-4615-8335 \\ walissonmo.msn@hotmail.com \\ Wesley Anderson Siqueira Ribeiro (iD) \\ Instituto Federal Goiano Campus Urutaí, Brasil \\ http://lattes.cnpq.br/4063527816946300 \\ http://orcid.org/0000-0003-4056-9798 \\ wesleyk13anderson@hotmail.com \\ Matheus Rocha Mendes (iD) \\ Instituto Federal Goiano Campus Urutaí, Brasil \\ http://lattes.cnpq.br/1430630633509461 \\ http://orcid.org/0000-0002-6308-7612 \\ matheus_engambiental@hotmail.com
}

\author{
Diego César Veloso Rezende (iD) \\ Instituto Federal Goiano Campus Urutaí, Brasil \\ http://lattes.cnpq.br/2390623769547865 \\ http://orcid.org/0000-0001-6176-0220 \\ diegoformiga@yahoo.com.br \\ Paulo Tárcyo de Resende Teixeira (DD \\ Instituto Federal Goiano Campus Urutaí, Brasil \\ http://lattes.cnpq.br/3582835679798961 \\ http://orcid.org/0000-0003-4898-6457 \\ paulotarcyo@hotmail.com
}

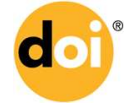

DOI: 10.6008/CBPC2179-6858.2020.001.0006

\section{Referencing this:}

SOUZA, J. A. R.; MOREIRA, D. A.; SILVA, É. L.; OLIVEIRA, W. M.; RIBEIRO, W. A. S.; MENDES, M. R.; REZENDE, D. C. V.; TEIXEIRA, P. T. R.. Riscos de contaminação e os impactos pela disposição de efluente de laticínios em latossolo vermelho amarelo. Revista Ibero Americana de Ciências Ambientais, v.11, n.1, p.54-62, 2020. DOI: http://doi.org/10.6008/CBPC2179-6858.2020.001.0006 


\section{INTRODUÇÃO}

Devido a intensificação da produção para atender a demanda da população por alimentos, houve, como consequência, o aumento da geração de resíduos, os quais se tornaram fonte de grande preocupação, pois na maior parte, passaram a ser lançados em curso d'água sem tratamento prévio, transformando-se em fonte poluidora dos mananciais e fator de risco para a saúde animal e humana (SOUZA et al., 2013).

Os cuidados com a preservação ambiental têm crescido em paralelo com o aumento da produção de resíduos, os quais têm sido utilizados na agricultura em substituição parcial ou total de fertilizantes minerais comerciais. Assim, a utilização de águas residuárias na agricultura têm surgido como uma alternativa para controle da poluição das águas superficiais e subterrâneas, além da disponibilização de água e fertilizantes para as culturas, ciclagem de nutrientes e aumento na produção agrícola, reduzindo os custos de produção e melhorando as características físicas, químicas e microbiológicas do solo (CAVALCANTI, 2012; LUCENA et al., 2018; OLIVEIRA et al., 2019).

Todavia, o uso incorreto pode trazer efeitos deletérios tanto ao solo quanto à cultura. A taxa de aplicação de águas residuárias deve estar baseada no nutriente que estiver em maior concentração relativa e na quantidade deste nutriente requerido pela cultura, pois, caso esses níveis sejam suplantados, além de comprometer a produtividade da cultura, podem provocar poluição do solo e das águas superficiais e subterrâneas (MATOS, 2016).

As principais alterações descritas para os solos fertirrigados com águas residuárias se resumem aos efeitos sobre o carbono e nitrogênio totais, atividade microbiana e N-mineral, cálcio e magnésio trocáveis, salinidade, sodicidade e dispersão de argilas (MATOS, 2016). Em resumo, a disposição de águas residuárias no sistema solo-planta, quando feita sem critérios agronômicos e ambientais, pode causar problemas de infiltração de água no solo, de contaminação do solo, das águas superficiais e subterrâneas e de toxicidade às plantas (ERTHAL et al., 2010).

O transporte de agroquímicos no solo pela água, para regiões localizadas abaixo do sistema radicular, além de caracterizar prejuízo econômico, pode comprometer a qualidade dos aquíferos subterrâneos. Sendo assim, o conhecimento da dinâmica da água e solutos no solo, em condições de não saturação é importante para a proposição de técnicas e medidas que, além de ganhos econômicos, viabilizem a exploração racional e a preservação dos recursos hídricos (GODOY et al., 2013).

A mobilidade dos íons no solo pode ser avaliada por meio de técnicas baseadas em deslocamento de fluidos miscíveis e recursos computacionais. Os modelos físico-matemáticos podem ser ajustados a dados experimentais oriundos de ensaios de lixiviação e eluição de íons em colunas de solo, em campo ou no laboratório, por meio de programas computacionais, tais como o Disp-1.1, desenvolvido por Borges Júnior et al. (2006). Tais modelos se constituem em ferramentas poderosas por possibilitarem a caracterização da mobilidade dos solutos no solo com base na dispersão, difusão e retardamento dos solutos em relação ao avanço da interface entre o líquido deslocador e o deslocado. 
O uso de águas residuárias constitui uma alternativa para a minimização dos impactos causados ao meio ambiente, uma vez que auxilia na conservação da água disponível, na maior disponibilidade no meio e na possibilidade de subsídio e reciclagem de nutrientes. Diante disso, vários pesquisados vêm estudando o transporte de solutos no solo. Alguns destes trabalhos reportam o deslocamento de cátions provenientes de diversos tipos de água residuária, tais como as domésticas (SANTOS et al., 2010; VILELA et al., 2017), as de suinocultura (SANTOS et al., 2010), do processamento dos frutos do cafeeiro (Ferreira et al., 2006), do processamento da mandioca (MELO et al., 2006) e vinhaça (SILVA et al., 2012; MATOS et al., 2013).

Assim, é muito importante o desenvolvimento de estudos que avaliem o comportamento dos íons presentes nas águas residuária quando dispostos no solo, uma vez que este conhecimento é essencial para estabelecer práticas de manejo de controle do movimento destes íons no solo evitando-se contaminação de águas subterrâneas, superficiais e do solo. Além disso, em razão da escassez de informações a respeito do deslocamento desses cátions em colunas constituídas por Latossolos, classe comumente encontrada no estado de Goiás, objetivou-se, com a realização deste trabalho, determinar o risco de contaminação e os impactos que podem causar os íons de sódio, potássio, cálcio e magnésio, presentes na água residuária de laticínios, por meio de ensaios em colunas de lixiviação.

\section{MATERIAIS E MÉTODOS}

O trabalho foi realizado no Instituto Federal Goiano - Campus Urutaí, em Urutaí - GO, localizado a $17^{\circ} 29^{\prime} 6^{\prime \prime} \mathrm{S}, 48^{\circ} 12^{\prime} 27^{\prime \prime} \mathrm{O}$ e altitude de $712 \mathrm{~m}$. Segundo a classificação de Köppen, o clima da região é do tipo Cwa, caracterizado como úmido tropical com inverno seco e verão chuvoso, com precipitação e temperatura médias, anuais, de $2000 \mathrm{~mm}$ e $28{ }^{\circ} \mathrm{C}$, e o solo da região é classificado como Latossolo vermelho amarelo (SILVA et al., 2015).

A água residuária de laticínios foi proveniente do Laticínios Valença (Laticínios JL Ltda), a qual foi conduzida até o IFGoiano, para realizar a caracterização de sua composição química e física, determinando os teores de potássio, sódio, cálcio, magnésio, condutividade elétrica, potencial hidrogeniônico, sólidos, demanda bioquímica de oxigênio (DBO) e demanda química de oxigênio (DQO) conforme metodologias recomendadas pela APHA (2012). Na Tabela 1 estão apresentadas as características médias da água residuária de laticínios utilizadas nos ensaios experimentais.

Tabela 1: Características físico-químicas das amostras dos efluentes de laticínios utilizados nos ensaios experimentais

\begin{tabular}{|l|l|}
\hline Parâmetros & Valores e desvio padrão \\
\hline $\mathrm{pH}$ & $4,70 \pm 0,70$ \\
\hline Sódio total $\left(\mathrm{mg} \mathrm{L}^{-1}\right)$ & $2534,70 \pm 509,91$ \\
\hline $\mathrm{CE}\left(\mu \mathrm{S} \mathrm{cm}^{-1}\right)$ & $2.025,50 \pm 607,30$ \\
\hline Sólidos totais $\left(\mathrm{mg} \mathrm{L}^{-1}\right)$ & $6.333,00 \pm 1.195,00$ \\
\hline $\mathrm{DQO}\left(\mathrm{mg} \mathrm{O}_{2} \mathrm{~L}^{-1}\right)$ & $8.437,00 \pm 1.536,0$ \\
\hline $\mathrm{DBO}_{5}\left(\mathrm{mgO}_{2} \mathrm{~L}^{-1}\right)$ & $3.374,80 \pm 952,0$ \\
\hline Fósforo total $\left(\mathrm{mg} \mathrm{L}^{-1}\right)$ & $393,35 \pm 74,50$ \\
\hline Potássio total $\left(\mathrm{mg} \mathrm{L}^{-1}\right)$ & $218,56 \pm 11,71$ \\
\hline Cálcio total $\left(\mathrm{mg} \mathrm{L}^{-1}\right)$ & $41,43 \pm 7,33$ \\
\hline Magnésio Total $\left(\mathrm{mg} \mathrm{L}^{-1}\right)$ & $184,39 \pm 53,85$ \\
\hline
\end{tabular}

Sendo: $\mathrm{pH}$ - potencial hidrogeniônico, DQO - demanda química de oxigênio, DBO - demanda bioquímica de oxigênio. CE- Condutividade Elétrica. 
As amostras de solo, foram coletadas na profundidade de $10-20 \mathrm{~cm}$ e conduzidas ao Laboratório de Pesquisa e Análises Químicas para determinação das características físicas e químicas, conforme metodologias descritas em Embrapa (1997). Na Tabela 2 estão apresentadas as características físicas e química do solo utilizado nos ensaios experimentais.

Tabela 2: Caracterização física e química do solo utilizado para condução do ensaio de lixiviação.

\begin{tabular}{|c|c|c|c|c|c|c|c|c|c|}
\hline \multirow{2}{*}{$\begin{array}{l}\text { Prof. } \\
(\mathrm{cm})\end{array}$} & \multirow[t]{2}{*}{$\mathrm{pH}$} & $P$ & $\mathrm{~K}$ & $\mathrm{Ca}$ & $\mathrm{Mg}$ & $\mathrm{Na}$ & \multirow{2}{*}{$\frac{\mathrm{MOS}}{\mathrm{g} \mathrm{kg}^{-1}}$} & \multirow{2}{*}{$\begin{array}{l}\text { VTP } \\
\mathrm{cm} \mathrm{h}^{-1}\end{array}$} & \multirow{2}{*}{$\begin{array}{l}\mathrm{KO} \\
\mathrm{g} \mathrm{cm}^{-3}\end{array}$} \\
\hline & & \multicolumn{5}{|c|}{$\mathrm{mg} \mathrm{dm}^{-3}$} & & & \\
\hline $10-20$ & 5,04 & 0,00 & 0 & 0,227 & 0,53 & 4,48 & 14,445 & 0,29 & 7,91 \\
\hline
\end{tabular}

pH-potencial hidrogeniônico; $\mathrm{p}=$ fósforo, $\mathrm{K}=$ potássio, $\mathrm{Na}=$ =sódio, $\mathrm{Ca}=$ Cálcio, Mg=Magnésio, MOS=matéria orgânica, VTPVolume Total de Poros, $\mathrm{KO}=$ Condutividade hidráulica.

Para avaliação de transporte de solutos presentes na água residuária de laticínios no solo foram conduzidos os estudos conforme metodologia apresentado por Almeida Neto et al. (2010). Para isso, foram utilizadas colunas de lixiviação confeccionados com tubos de PVC com 4,7 cm de diâmetro e 20,0 cm de comprimento, cujas paredes internas foram cobertas com uma mistura de cola e areia, a fim de impedir o escoamento preferencial. Na extremidade inferior das colunas foram dispostos disco de lã de vidro e uma tela plástica, para impedir a perda de material sólido, enquanto na camada superior, utilizou-se apenas uma lã de vidro a fim de se evitar alterações superficiais.

As colunas foram preenchidas a partir da deposição sucessiva de camadas de solo com dois centímetros de espessura e sua posterior compactação no interior do tubo de PVC até formação de uma coluna com 0,15 m de altura. A compactação foi realizada de modo a se obter massa específica semelhante àquela anteriormente determinada pelo método da proveta, obtendo-se uma coluna homogênea e evitando a ocorrência de fluxo preferencial dentro da coluna de solo. Para determinação do volume de poros foi utilizado a Equação 1.

(1) $V p=\alpha V=\pi r^{2} h\left(1-\frac{\rho_{s}}{\rho_{p}}\right)$

em que:

Vp - volume de poros, $\mathrm{cm}^{3}$ $V$ - volume da coluna de solo, $\mathrm{cm}^{3}$ $\alpha$ - porosidade, $\mathrm{cm}^{3} \mathrm{~cm}^{-3}$; $r$ - raio interno da coluna, $\mathrm{cm}$; $\mathrm{h}$ - altura da coluna de solo, $\mathrm{cm}$; $\rho_{\mathrm{s}}$ - massa específica do solo, $\mathrm{g} \mathrm{cm}^{-3}$; e $\rho_{p}$ - massa específica das partículas do solo, $\mathrm{g} \mathrm{cm}^{-3}$.

Posteriormente, as colunas foram saturadas com água destilada, colocando-as dentro de um recipiente com altura de lâmina equivalente a $2 / 3$ da coluna e deixando-as em repouso por $72 \mathrm{~h}$, conforme recomendações de Ferreira (1987), promovendo-se, assim, a expulsão de bolhas de ar que pudessem obstruir o fluxo da solução nos poros.

A seguir, as colunas foram interligadas a frascos de Mariotte contendo água destilada, por um período suficiente para passar dois volumes de poros. Após completa infiltração da água destilada, os frascos de Mariotte contendo a água residuária foram interligados às colunas de solo. $\mathrm{O}$ sistema foi montado de modo a aplicar, simultaneamente, água residuária de laticínios em quatro diferentes concentrações de sódio 
(250; 625; 1250; $2500 \mathrm{mg} \mathrm{L}^{-1}$ de Na), obtidas a partir do efluente bruto (bruto e diluições em 2, 4 e 10 vezes, com água destilada). O efluente era homogeneizado frequentemente para evitar que a parte sólida decantasse no reservatório no momento da aplicação. A aplicação do efluente foi feito por meio de frascos de Mariotte, posicionados próximos à extremidade superior das colunas, mantendo-se uma carga hidráulica média de 0,02 m. O experimento foi montado e conduzido, por três vezes.

Para obtenção das curvas de efluente, os lixiviados dos frascos de Mariotte foram coletados em frascos de numeração sequenciada e volumes conhecidos, determinando-se as concentrações de $\mathrm{Na}, \mathrm{Ca}, \mathrm{Mg}$ e K por espectrofotometria de absorção atômica. De posse da correlação entre os dados de concentração relativa $C / C_{0}$ (relação entre a concentração iônica no efluente e no lixiviado) e o volume de poros, além do fluxo, massa específica do resíduo, teor de água e comprimento da coluna, foram determinados o fator de retardamento $(R)$ e o coeficiente dispersivo-difusivo (D), por meio do programa computacional DISP 1.1 (BORGES JUNIOR et al., 2006).

\section{RESULTADOS E DISCUSSÃO}

A partir do conhecimento das propriedades e das interações de determinada substância química com o meio, e de sua movimentação e persistência no solo, é possível se prever os riscos de contaminação e os impactos que ela possa causar ao meio ambiente (COSTA et al., 1999). De acordo com Anami et al. (2008), o conhecimento da dinâmica da água e solutos no solo em condições de não saturação, é importante para a proposição de técnicas e medidas que, além de ganhos econômicos, possam viabilizar a exploração racional e a preservação dos recursos hídricos. Nas Figuras 1 (a, b, c e d), estão apresentadas as curvas de efluente para cálcio, magnésio, potássio e sódio, obtidas com o Latossolo Vermelho Amarelo pelo ajustamento do modelo teórico aos dados experimentais.

O número de volume de poros correspondente à concentração relativa 0,5 é uma primeira indicação, no sentido da existência ou não de interações soluto-solo (FERREIRA et al., 2006). De acordo com Nielsen et al. (1962), quando o valor é maior que 1,0, ocorre interação do soluto com a fração coloidal do solo. Assim, analisando-se a Figura 1, verifica-se que, para todas as concentrações de água residuária de laticínios e para todos os íons avaliados, a exceção do íon magnésio utilizando-se o efluente bruto, a concentração relativa de 0,5 ocorreu em valores de números de poros superiores a 1, indicando que ao escoar através do perfil do solo, parte do soluto é adsorvida, resultando um fator de retardamento acima da unidade. Portanto, quanto maior é o fator de retardamento maior será a interação soluto-solo.

Na Tabela 3 estão apresentados os parâmetros de transporte dos íons cálcio, magnésio, potássio e sódio, obtidos pelo ajustamento do modelo teórico aos dados experimentais, utilizando-se o programa computacional DISP (BORGES JUNIOR et al., 2006). 

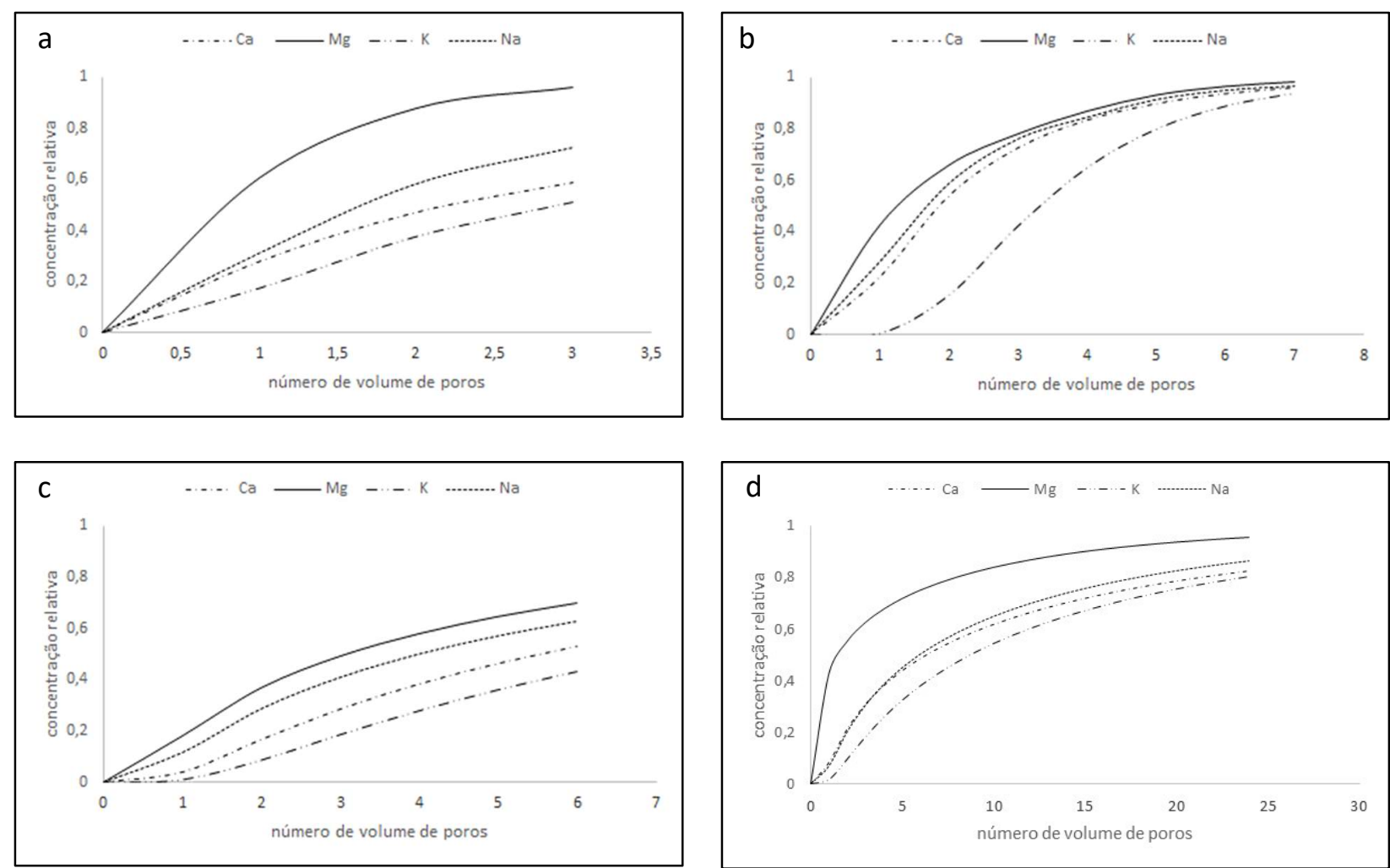

Figura 1: Curvas de efluente cálcio $(\mathrm{Ca})$, magnésio $(\mathrm{Mg})$, potássio $(\mathrm{K})$ e sódio $(\mathrm{Na})$ presentes na água residuária de laticínios bruta (a), diluída duas vezes (b), quatro vezes (c) e dez vezes (d), ajustada aos dados experimentais, obtidos com latossolo vermelho amarelo.

Tabela 3: Fator de retardamento (fR) e coeficiente dispersivo-difusivo (D) dos íons de cálcio, magnésio, sódio e potássio, obtidos pelo ajustamento do modelo teórico aos dados experimentais.

\begin{tabular}{|c|c|c|c|c|c|c|c|c|c|c|c|c|}
\hline \multirow[t]{2}{*}{ Efluentes } & \multicolumn{3}{|l|}{ Cálcio } & \multicolumn{3}{|c|}{ Magnésio } & \multicolumn{3}{|c|}{ Potássio } & \multicolumn{3}{|l|}{ Sódio } \\
\hline & Peclet & $f R$ & $D$ & Peclet & $f R$ & $D$ & Peclet & $f R$ & $D$ & Peclet & $f R$ & $\mathrm{D}$ \\
\hline bruto & 1,04 & 2,22 & 77,90 & 3,05 & 0,82 & 26,57 & 1,41 & 2,93 & 57,45 & 1,93 & 1,64 & 41,97 \\
\hline $2 x$ & 2,97 & 1,84 & 27,27 & 1,73 & 1,26 & 46,82 & 8,06 & 3,30 & 10,05 & 2,63 & 1,64 & 30,80 \\
\hline $4 x$ & 1,65 & 5,56 & 49,09 & 1,19 & 3,07 & 68,07 & 2,00 & 7,10 & 40,50 & 1,27 & 4,00 & 63,78 \\
\hline $10 x$ & 0,85 & 6,35 & 95,29 & 0,4 & 1,5 & 202,5 & 1,31 & 8,74 & 61,83 & 1,06 & 5,94 & 76,42 \\
\hline
\end{tabular}

Sendo: bruto - efluente bruto, $2 x$ - efluente diluído 2 vezes, $4 x$ - efluente diluído 4 vezes, 10x - efluente diluído 10 vezes, Peclet - número de Peclet , $f R$, fator de retardamento, $D$ - coeficiente dispersivo-difusivo.

Analisando a Tabela 3, verifica-se que a água residuária de laticínios, em todas as concentrações avaliadas, resultou em valores de número de Peclet inferior a 10, que conforme classificação proposta por Gonçalves (2008), indicam predominância do transporte convectivo dos íons avaliados através do perfil do solo. Também, observa-se que o fator de retardamento apresentou valores superiores a unidade, a exceção do íon magnésio no efluente bruto, o que conforme Ferreira et al. (2006), indica baixa mobilidade dos íons e uma elevada interação solo-soluto.

Matos et al. (2013) estudando o deslocamento de íons provenientes da vinhaça em colunas lixiviação também observaram fator de retardamento para o íon magnésio abaixo do valor unitário, indicando não ter havido interação do soluto com a fração coloidal dos solos, sendo justificado pelo fraco poder competidor deste cátion pelos sítios de troca do solo.

Analisando-se o coeficiente dispersivo-difusivo para um mesmo íon, verifica-se que houve incrementos nos valores deste coeficiente com aumento das diluições do efluente, o que possivelmente está 
relacionado com as concentrações dos íons presentes na água de diluição, uma vez que apresentou teores dissolvidos iguais a 13; 10; 6,5 e 17,5 $\mathrm{mg} \mathrm{L}^{-1}$ para o cálcio, magnésio, potássio e sódio, respectivamente.

De acordo com Ferreira et al. (2006) e Matos et al. (2013), para uma mesma velocidade média de escoamento de uma solução, valores mais elevados do coeficiente dispersivo-difusivo correspondem a uma menor declividade da curva de efluente, em virtude da maior mistura na interface entre os fluidos deslocado e deslocador. Assim, verifica-se que, para uma mesma concentração do efluente, a preferência de interação foi $\mathrm{K}>\mathrm{Ca}>\mathrm{Na}>\mathrm{Mg}$.

A sequência de preferência observadas seguiu a ordem de reatividade dos íons avaliados, ou seja, quanto mais reativo foi o íon, maior foi sua preferência de troca (ATKINS et al., 2012). Ferreira et al. (2006) estudando o transporte de íons presentes na água residuária de café conilon aplicadas em diferentes tipos de solo e, Matos et al. (2013), ao aplicarem água residuária de vinhaça em diferentes tipos de latossolos, verificaram que a preferência de interação foi $\mathrm{K}>\mathrm{Ca}>\mathrm{Mg}>$ para o latossolo.

Esses resultados alertam para interação entre os solutos presentes na água residuária de laticínios com o solo, podendo, em caso de aplicação inadequada, tornar o solo salino com a possibilidade provocar excesso de potássio nas camadas superiores do solo, e de sódio nas camadas inferiores, resultando em salinização do lençol freático devido a lixiviação do sódio.

Embora o potássio seja essencial em quase todos os processos necessários ao crescimento e reprodução das plantas, além de proporcionar maior resistência ao ataque de pragas e doenças, estiagens, excesso de água, elevações ou reduções de temperaturas ambientes (NOVAIS et al., 2007; GOMES et al., 2015), quando em excesso, pode interferir no crescimento das plantas em virtude do efeito osmótico e da toxicidade de íons específicos presentes na solução (FREIRE et al., 2003; ANDRIOLO et al., 2010 ), bem como limitar a absorção de cálcio, enxofre, fósforo e sódio, inibir a absorção de magnésio e causar deficiência de zinco (MALAVOLTA et al., 1997).

A elevada mobilidade do sódio e associada a baixa interação deste íon presente na água residuária de laticínios com o latossolo pode tornar a água freática salina e com excesso de sódio, ficando inadequada para consumo e, caso ingerida, provocar retenção de água no corpo, com o aumento do volume hídrico no seu interior, o que acarretará na elevação da pressão arterial. Em consequência do acúmulo de sódio no interior do corpo humano, esse mineral provoca alguns problemas de saúde, tais como: câncer, problemas renais, cardíacos e também acidente vascular cerebral (AVC) (WYNESS et al., 2012; WHO, 2013)

Todavia, ainda são pouco frequentes na literatura, trabalhos que apresentam dados sobre os impactos negativos provocados pelo uso dessas águas ao solo e aos mananciais. Dentre os artigos que tratam sobre o transporte de solutos em colunas de solo destacam os de Gomes et al. (2004), Silva et al. (2015), Melo et al. (2006), Godoy et al. (2013), dentre outros; no entanto, nenhuma pesquisa foi identificada sobre o deslocamento de cátions provenientes de águas residuárias laticínios, em colunas de solo. 


\section{CONCLUSÕES}

De acordo com as condições experimentais, pode-se concluir que: Os ensaios em colunas de lixiviação demonstraram a preferência de interação de $\mathrm{K}>\mathrm{Ca}>\mathrm{Na}>\mathrm{Mg}$, independentemente da diluição do efluente, seguindo-se a ordem de reatividade dos íons. Esses resultados alertam para interação entre os solutos presentes na água residuária de laticínios com o solo, podendo, em caso de aplicação inadequada, tornar o solo salino com a possibilidade provocar excesso de potássio nas camadas superiores do solo, e de sódio nas camadas inferiores, resultando em salinização do lençol freático devido a lixiviação do sódio.

AGRADECIMENTOS: pelo apoio financeiro concedido pelo Instituto Federal Goiano Campus Urutaí e a PROPPI.

\section{REFERÊNCIAS}

ALMEIDA NETO, O. B.; MATOS, A. T.; MATOS, V. P.; LAMBERT, T. F.; DIAS, E. F.. Influência da qualidade da água no comportamento dispersivo da argila do latossolo vermelho-amarelo. Engenharia na agricultura, Viçosa, v.18, n. 3,2010

APHA. American Public Health Association. Standard Methods for the Examination of Water and Wastewater. 22. ed. New York: APHA, 2012.

ANAMI, M. H.; SAMPAIO, S. C.; SUSZEK, M.; GOMES, S. D.; QUEIROZ, M. M. F.. Deslocamento miscível de nitrato e fosfato proveniente de água residuária da suinocultura em colunas de solo. Revista Brasileira de Engenharia Agrícola e Ambiental, v.12, n.1, p.75-80, 2008. DOI: http://dx.doi.org/10.1590/S1415-43662008000100011

ANDRIOLO, J. L.; JÄNISCH, D. I.; SCHMITT, O. J.; DAL PICIO, M.; CARDOSO, F. L.; ERPEN, L.. Doses de potássio e cálcio no crescimento da planta, na produção e na qualidade de frutas do morangueiro em cultivo sem solo. Ciência Rural, Santa Maria, v.40, n.2, p.267-272, 2010. DOI: http://dx.doi.org/10.1590/S0103-84782010000200003

ATKINS, P.W.; JONES, L.. Princípios de química: questionando a vida moderna e o meio ambiente. Animal, v.4, n.1, p.185203, 2012

BORGES JUNIOR, J. C. F.; FERREIRA, P. A.. Equações e programa computacional para cálculo do transporte de solutos no solo. Revista Brasileira de Engenharia Agrícola e Ambiental, v.10, n.3, p.604-611, 2006.

CAVALCANTI, J. E.. Manual de Tratamento de Efluentes Industriais. 2 ed. São Paulo: J. E. Cavalcanti, 2012.

COSTA, S. N.; MARTINEZ, M. A.; MATOS, A. T.; RAMOS, V. B. N.. Mobilidade de nitrato em coluna de solo sob condições de escoamento não permanente. Revista Brasileira de Engenharia Agrícola e Ambiental, v.3, n.2, p.190-194, 1999. DOI: http://dx.doi.org/10.1590/1807-

1929/agriambi.v3n2p190-194

OLIVEIRA, J. F.; FIA, R.; FIA, F. R. L.; RODRIGUES, F. N.; OLIVEIRA, L. F. C.; FILHO, L. C. A. L.. Efeitos da água residual de laticínios na respiração basal do solo, produtividade e remoção de nutrientes por Tifton 85 (Cynodon sp.). Rev. de Ciências Agrárias, v.42, n.1, p.155-160, 2019.

EMBRAPA. Centro Nacional de Pesquisa de Solos. Manual de métodos de análise de solo. 2 ed. Rio de Janeiro: EMBRAPA, 1997.

ERTHAL, V. J. T.; FERREIRA, P. A.; MATOS, A. T.; PEREIRA, O. G.. Alterações físicas e químicas de um Argissolo pela aplicação de água residuária de bovinocultura. Revista Brasileira de Engenharia Agrícola e Ambiental, v.14, n.5, p.467-477, 2010.

FERREIRA, P. A.. Drenagem. Brasília: ABEAS, 1987.

FERREIRA, P. A.; GARCIA, G. O.; MATOS, A. T.; RUIZ, H. A.; BORGES JUNIOR, J. C. F.. Transporte no solo de solutos presentes na água residuária de café conilon. Acta Scientiarum - Agronomy, v.28, p.29-35, 2006. DOI: http://dx.doi.org/10.4025/actasciagron.v28i1.1295

FREIRE, M. B. G. S.; RUIZ, H. A.; RIBEIRO, M. R.; FERREIRA, P. A.; VICTOR, H.; ALVAREZ, V.; FREIRE, F. J.. Condutividade hidráulica de solos de Pernambuco em resposta à condutividade elétrica e RAS da água de irrigação. Revista Brasileira de Engenharia Agrícola e Ambiental, Campina Grande, v.7, n.1, p.45-52, 2003. DOI: http://dx.doi.org/10.1590/S1415-43662003000100008

GODOY, V. A.; ZUQUETTE, L. V.. Avaliação do retardamento de fosfato em colunas indeformadas de solo residual arenoso de área irrigada com efluente de tratamento de esgotos. Periódico Eletrônico Fórum Ambiental da Alta Paulista, v.9, n.11, 2013. DOI: http://dx.doi.org/10.17271/198008279112013667

GOMES, E. R. S.; SAMPAIO, S. C.; CORRÊA, M. M.; BOAS, M. A. V.; ALVES, L. F. A.; ALVES SOBRINHO, T.. Movimento de nitrato proveniente de água residuária em colunas de solo. Revista Engenharia Agrícola, v.24, n.3, p.557-568, 2004.

GOMES, E. R.; BROETTO, F.; QUELUZ, J. G. T.; BRESSAN, D. F.. Efeito da fertirrigação com potássio sobre o solo e produtividade do morangueiro. Irriga, Botucatu, v.1, n.1, 
p.107-122, 2015. DOI:

https://doi.org/10.15809/irriga.2015v1n1p107

GONÇALVES, A. D. M. A.; MIRANDA, P. R.; SABADIN, J. F. G.; KAMOGAWA, M. Y.. Temperature effect in potassium and nitrate íons in soil transport. Engenharia Agrícola, v.28, p.438-447, 2008.

LUCENA, C. Y. D. S.; SANTOS, D. J. R.; SILVA, P. L. S.; COSTA, E. D.; LUCENA, R. L.. O reúso de águas residuais como meio de convivência com a seca no semiárido do Nordeste Brasileiro. Revista de Geociências do Nordeste, v.4, p.1-17, 2018.

MALAVOLTA, E.; VITTI, G. C.; OLIVEIRA, S. A.. Avaliação do estado nutricional das plantas: princípios e aplicações. 2 ed. Piracicaba: POTAFOS, 1997.

MATOS, A. T.; GARIGLIO, H. A. A.; LO MONACO, P. A. V.. Deslocamento miscível de cátions provenientes da vinhaça em colunas de solo. R. Bras. Eng. Agríc. Amb., v.17, v.7, p.743-749, 2013. DOI: http://dx.doi.org/10.1590/S141543662013000700008.

MATOS, A. T.; MATOS , M. P.. Disposição de águas residuárias no solo e em sistemas alagados construídos. Viçosa: UFV, 2016.

MELO, R. F.; FERREIRA, P. A.; MATOS, A. T.; RUIZ, H. A.; OLIVEIRA, L. B.. Deslocamento miscível de cátions básicos provenientes da água residuária de mandioca em colunas de solo. Revista Brasileira de Engenharia Agrícola e Ambiental, v.10, n.2, p.456-465, 2006.

NIELSEN, D. R.; BIGGAR, J. W.. Missible Displacemente: III Theoretical considerations. Soil Sci. Soc. Am. J., Madison, v.26, p.216211, 1962.
NOVAIS, R. F.; ALVAREZ, V. V. H.; BARROS, N. F.; FONTES, R. L. F.; CANTARUTTI, R. B.; NEVES, J. C. L.. Fertilidade do solo. Viçosa: Sociedade Brasileira de Ciência do Solo, 2007.

SANTOS, J. S.; LIMA, V. L. A.; JUNIOR, J. C. F. B.; SILVA, L. V. B. D.; AZEVEDO, C. A. V.. Mobilidade de solutos em colunas de solo com água residuária doméstica e de suinocultura. Revista Brasileira de Engenharia Agrícola e Ambiental, v.14, n.11, p.1226-1233, 2010.

SILVA, A. A. F.; SOUZA, J. A. R; CARVALHO, W. B.; MENDONÇA, R. B.; MOREIRA, D. A.. Distribuição da umidade do solo num sistema irrigado por gotejamento superficial com diferentes inclinações do terreno. REVENG Engenharia na agricultura, Viçosa, v.23, n.3, p.261-269, 2015.

SOUZA, J. A. R.; MOREIRA, D. A.; MATOS, A. T.; RODRIGUES, A. S. L.. Effect of irrigation with wastewater from swine in the chemical properties of a latossol. African Journal of Agricultural Research, v.8, p.5166-5173, 2013. DOI: https://doi.org/10.5897/AJAR2013.7078

VILELA, N. M. S.; THEBALDI, M. S.; LEAL, B. P.; SILVA, A. V.; MARTINS, I. P.. Parâmetros de transporte do potássio presente em esgotos sanitários dispostos em colunas de solo. Engenharia Agrícola, v.38, n.1, 2017.

WHO. World Health Organization. WHO issues new guidelines on dietary salt and potassium. Genebra: WHO, 2013.

WYNESS, L. A.; BUTRISS, J. L.; STANNER, S. A.. Reducing the population's sodium intake. The UK Food Standards Agency's salt reduction programme. Public Health Nutrition, v.15, n.11, p.254-261, 2012. DOI: https://doi.org/10.1017/S1368980011000966

A CBPC - Companhia Brasileira de Produção Científica (CNPJ: 11.221.422/0001-03) detém os direitos materiais desta publicação. Os direitos referem-se à publicação do trabalho em qualquer parte do mundo, incluindo os direitos às renovaç̃os, expansões e disseminações da contribuiç̃o, bem como outros direitos subsidiários. Todos os trabalhos publicados eletronicamente poderão posteriormente ser publicados em coletâneas impressas sob coordenação da Sustenere Publishing, da Companhia Brasileira de Produção Científica e seus parceiros autorizados. Os (as) autores (as) preservam os direitos autorais, mas não têm permissão para a publicação da contribuição em outro meio, impresso ou digital, em português ou em tradução. 